\title{
Serebral palsi rehabilitasyonundaki yenilikler
}

\author{
Innovations in cerebral palsy rehabilitation
}

\author{
Özlem El \\ Dokuz Eylül Üniversitesi Tıp Fakültesi, Fiziksel Tıp ve Rehabilitasyon Ana Bilim Dalı, İzmir
}

\begin{abstract}
Çocukluk çağının en sık görülen engellilik nedeni olan serebral palsi konusunda erken tanı, önleme ve tedavi ile ilgili çok önemli gelişmeler olmuştur. Neonatal hipotermi uygulamaları, antenatal uygulanan kortikosteroid tedavisi, preterm doğan ve mekanik ventilasyon uygulanacak olan infantlara entübasyon öncesi profilaktik kafein (metilksantin) uygulamasının perinatal asfiksi ve neonatal ensefalopati bulguları olan infantlarda serebral palsi gelişimini engellemektedir. Epidemiyolojik çalışmalar şiddetli motor etkilenmesi olan ambulatuvar olmayan olguların görülme oranının azaldığını göstermektedir. Bu sonuçlar kapsamlı obstetrik ve neonatal yoğun bakım uygulamaları ile başarılmaktadır. Önleme ve yoğun bakım sürecindeki bu gelişmeler ile birlikte serebral palsi riskinin erkenden saptanması rehabilitasyon stratejilerinin, erken girişim yaklaşımlarının uygulanmaya başlaması da riskli bebeklerin tedavisinde çok önemli bir adımdır. Serebral palsi rehabilitasyonu randomize kontrollü çalışmanın çok fazla yapılmaya başladığı bir alan olmuştur. Bu da geçmişten bu yana uygulanan yöntemlerin etkinliğinin anlaşılmasına, plastisite kavramının ve ICF (The International Classification of Functioning, Disability and Health) temelli yaklaşımın ön plana çıkması ile rehabilitasyonda bakış açısının değişmesine katkıda bulunmuştur. Rehabilitasyon stratejileri de pasif tedavi yaklaşımlarından giderek hastaya özel, aktivite temelli ve hedefe yönelik tedavi kombinasyonları şeklinde planlanmaya başlamıştır. $\mathrm{Bu}$ derlemede yeni uygulanmaya başlanan popüler rehabilitasyon yöntemleri yanında klasik uygulanan yöntemlerle ilgili en son kanıt düzeylerine de değinilecektir.
\end{abstract}

Anahtar sözcükler: serebral palsi; rehabilitasyon; fizik tedavi; yenilikler

\begin{abstract}
There have been particularly important developments in early diagnosis, prevention and treatment of cerebral palsy, which is the most common cause of disability in childhood. There are high-quality studies showing that neonatal hypothermia practices, antenatal corticosteroid treatment, prophylactic caffeine (methylxanthine) administration before intubation in infants born preterm and who will undergo mechanical ventilation prevents the development of cerebral palsy in infants with perinatal asphyxia and neonatal encephalopathy findings. Epidemiological studies show that the incidence of non-ambulatory cases with severe motor impairment has decreased. These results are achieved with comprehensive obstetric and neonatal intensive care practices. With these developments in the prevention and intensive care process, early detection of cerebral palsy risk, the introduction of rehabilitation strategies and early intervention approaches is a very important step in the treatment of risky babies. Cerebral palsy rehabilitation has become an area where randomized controlled trials have begun to be done a lot. This has contributed to the understanding of the effectiveness of the methods applied since the past and to the prominence of the concept of plasticity and the ICF (The International Classification of Functioning, Disability and Health) based approach and the change of perspective in rehabilitation. Rehabilitation strategies have started to be planned as patient-specific, activity-based and target-oriented therapy combinations, from passive treatment approaches. In this review, the most recent evidence levels regarding conventionally applied methods will be discussed along with the newly introduced popular rehabilitation methods.
\end{abstract}

Key words: cerebral palsy; rehabilitation; physical therapy; innovation
Ç. ocukluk çağının en sık görülen engellilik nedeni olan serebral palsi konusunda erken tanı, önleme ve tedavi ile ilgili çok önemli gelişmeler olmuştur. Neonatal hipotermi uygulamaları, antenatal uygulanan kortikosteroid tedavisi, preterm doğan ve mekanik ventilasyon uygulanacak olan infantlara entübasyon öncesi profilaktik kafein (metilksantin) uygulamasının perinatal asfiksi ve neonatal ensefalopati bulguları olan infantlarda serebral palsi gelişimini engellediğini gösteren yüksek kalitede çalışmalar mevcuttur. ${ }^{[1]}$ Çocukluk çağının en sık görülen gelişimsel bozukluğu olan serebral palsi “Dünya

- İletişim adresi: Prof. Dr. Özlem El, Dokuz Eylül Üniversitesi Tıp Fakültesi Fiziksel Tıp ve Rehabilitasyon Ana Bilim Dalı İnciraltı, Balçova, İzmir Tel: 0232 - 4123958 e-posta: ozlem.el@deu.edu.tr 
Sağlık Örgütü" tarafından "Uluslararası İşlevsellik Özürlülük ve Sağlık Sınıflaması"nda aktivite ve katılım hakkında değişen görüşlerle birlikte 2004 yılında "gelişmekte olan ya da infant beyninde ortaya çıkan, progresif olmayan, aktivite kısıtlamasına neden olan, bir grup kalıcı hareket ve postür bozukluğu" olarak tanımlanmıştır. ${ }^{[2]}$ Tanımlamadaki değişiklikler ile birlikte rehabilitasyon uygulamalarında da bakış açısı değişmiş ve iki binli yılların başından itibaren aktivite temelli yaklaşımlar kabul görmeye başlamıştır. Geleneksel rehabilitasyon yaklaşımları yerine yoğun aktif egzersiz protokolleri, hayat tarzı modifikasyonları ve hareketliliği geliştirici cihazların kulanımı ön plana çıkmaktadır. Motor aktivitenin artırılması ile fiziksel ve mental sağlığın, bilişsel performansın iyileştiği, nöral ve işlevsel iyileşmenin uyarıldığı gösterilmiştir. ${ }^{[3,4]}$

Serebral palsi yaşam boyu süren bir durum olduğundan, çocuğun büyümesi ile işlevsel durum ve gereksinimlerinde değişiklikler meydana gelir. Klinik durum çok çeşitli klinik tiplerde karşımıza gelebilir. Aktivite kısıtlanması ve katılımdaki zorlukların azaltılabilmesi için planlanan tedavi yaklaşımları konservatif ya da cerrahi olabilir ve tedavinin dinamik bir süreç içinde olan hastada planlandığı unutulmamalıdır. Serebral palsili çocuk ve erişkinlerde yapılan az sayıda çalışmada, bu hastalarda psikopatolojik problemlerin, ağrının ve motor yetersizliğin, hem çocuk ve hem de ailede düşük yaşam kalitesinin yüksek oranlarda olduğu vurgulanmıştır. Bu durumda çok erken dönemden başlayan habilitasyon/rehabilitasyon programlarının etkinliğinin uzun dönemde sorgulanması önemlidir. Rehabilitasyon programlarının başarısı hastanın gereksinimleri çerçevesinde belirlenmesine, hasta ve aile odaklı olmasına, uygulanabilir ve sürdürülebilir olmasına, çocuğun sosyal hayata katılımını desteklemesine bağlıdır. Sonuçlarının değerlendirilmesinin önemi de vurgulanmaktadır. ${ }^{[5]}$

Günümüzde erken girişim programları riskli bebeklerde 0-5 yaş arasında çocuğun sağlıklı gelişimine katkı sağlamak, mevcut ya da ortaya çıkacak işlevsel bozuklukları önlemek, aileyi eğitmek ve sürece uyum sağlamasına yönelik olarak planlanmaktadır. Prematüre bebeklerde erken girişim programlarının bilişsel ve motor fonksiyonlar üzerinde etkili olduğu ve bilişsel fonksiyonlardaki etkinin okul öncesi döneme kadar sürdüğü görülmüştür. Bu programların etkilerinin girişim programının özelliğinden bağımsız olarak ortaya çıktığı bir Cochrane derlemesinde bildirilmiştir. ${ }^{[6]}$ Erken girişim, çocukluk dönemini kapsayan tüm rehabilitasyon çalışmalarını ifade eder. Önceleri primer olarak motor beceriler üzerine odaklanılırken, son yıllarda aile odaklı yaklaşım ve işlevsel kazanımlar ön plana çıkmıştır. Geleneksel yaklaşımlarda eski bakış açısı ile hedeflenen hareketi normale döndürme, kaliteli hale getirme çabası iken özellikle iki binli yıllardan sonra işlevselliğe odaklanma hedeflenmiştir. ${ }^{[3,4]}$ işlevsel yaklaşımda, yetersiz işlevsel aktivitelerin iyileştirilmesine odaklanılır. Çocuk, işlevsel bir görev için tüm olanakları keşfetmek ve en iyi stratejik çözümleri bulmak için rehabilitasyon programına aktif olarak katılmalıdır. Performansı artırmak için çocuk ve aileye yardımcı olunur. Aile, hedef belirlemede ve günlük hayata adapte etmekten değerlendirmeye kadar programın tüm aşamalarına katılır. Bu şekilde yapılan rehabilitasyon uygulamalarının günlük yaşama aktarılabilmesi ve terapi seansları sonrasında da kullanılabilmesi açısından klasik rehabilitasyon programlarına üstün olduğu gösterilmiştir. ${ }^{[7]}$ En sık kullanılan geleneksel tedavi yaklaşı$\mathrm{m}$ ı olan Bobath tekniğinin de Bobath konsepti olarak klasik yaklaşımdan güncel görüşe uygun özelliklerle geliştirildiği söylenmektedir. ${ }^{[3,4]}$

\section{ÜST EKSTREMITE FONKSIYONUNU GELIŞTIREN TEDAVI YAKLAŞIMLARI}

Serebral palsili çocukların \%60'ından fazlasında üst ekstremite fonksiyonlarında bilateral etkilenme mevcuttur. ${ }^{[8]}$ Cisimlerin elle tutulup kullanılmasındaki sorunların çocukların günlük aktivitelerinde ve katılımlarındaki en önemli sınırlayıcılar arasında olduğu bildirilmektedir. Özellikle asistif (yardımcı) cihaz kullanımında da önemli olan üst ektremite sorunlarının tedavisinde zorunlu kullanım tedavisi, bimanuel tedavi, sanal gerçeklik ve bilgisayar destekli tedaviler, iş meşguliyet tedavileri ve bu tedavilerin botulinum toksin uygulamaları ile kombine edilmesi öne çıkan ve etkinlikleri gösterilen tedavi yaklaşımlarıdır. ${ }^{\left[{ }^{[]}\right.}$

\section{Kısıtlamalı Zorunlu Kullanım Tedavisi ve Bimanuel Tedavi}

Bu iki tedavi yöntemi de özellikle üst ekstremitede tek taraflı etkilenmesi belirgin olan hemiplejik tip serebral palsili çocuklarda kullanılan motor öğrenme temelli tedavi yöntemleridir. Daha az etkilenmiş ya da etkilenmemiş ekstremitenin günlük yaşamda daha fazla kullanımı, gelişimsel ihmal fenomeninin ortaya çıkmasına neden olabilir. Bu şekilde sağlam serebral hemisferin aktivasyonu ile ortaya çıkan anormal interhemisferik inhibisyon etkilenmiş tarafın daha fazla inhibe olmasına ve motor iyileşmenin yetersiz kalmasına neden olmaktadır. Zorunlu kullanım tedavisi, dominant üst ekstremitenin sınırlanması ve etkilenmiş olan üst ekstremitenin yoğun ve göreve özgün olarak çalıştırılması esasına dayanan bir yöntemdir. 2004 yılında ilk randomize kontrollü çalışmanın yayımlanmasından sonra özellikle hemiplejik tip serebral palsili 
çocuklarda çok fazla randomize kontrollü çalışma ile etkinliği gösterilmiştir. ${ }^{[9]} \mathrm{Haftada} 2-7$ gün arasında, günde $2-10$ saat ve $2-8$ hafta arasında değişen tedavi protokolleri mevcuttur. En sık 2-3 hafta günde 6 saat uygulamaların yapıldığı kamp şeklindeki katılımlar yaygın olarak kullanılmaktadır. ${ }^{[10]} \mathrm{Bu}$ şekilde çocukların motivasyonunun ve uygulamanın etkinliğinin artırılması mümkün olmaktadır. Kısıtlamalı zorunlu kullanım tedavisinin uygulanabilmesi için el bileğinde biraz aktif ekstansiyon ve elde kavrama yeteneği olması gerekmektedir. Kullanılan kısıtlama yöntemi alçı, atel, omuz askısı, eldiven şeklinde olabilmektedir ve bu yöntemlerin birbirine herhangi bir üstünlüğü gösterilememiştir. Kısıtlamalı zorunlu kullanım tedavisinin yararları ile ilgili güçlü kanıtlar olmasına karşın bu tedavi yönteminde tek ekstremite ile yoğun egzersiz yapılması nedeni ile sağlam ve etkilenmiş elin bilateral kullanımında, koordinasyonunda ve motor planlamada gelişme elde etmek için bimanuel tedavi yaklaşımı gündeme gelmiştir. Bu tedavilerde de yapılan yoğun uygulamalar ile bimanuel performansta iyileşmeler bildirilmiştir. Bimanuel tedavinin zorunlu kullanım tedavisi sonrasında ardışık olarak planlanması amaca yönelik bilateral kullanımı artırmıştır. ${ }^{[11]} \mathrm{Hem}$ zorunlu kullanım ve hem de bilateral el-üst ekstremite kullanı$\mathrm{m}$ ile işlevsel iyileşmenin olması için tedavinin yüksek dozlarda (çok tekrarlı ve uzun zamanlı) uygulanması gerektiği bildirilmektedir. Ancak bu tedavilerin çocuk tarafından kabul edilebilir ve uygulanabilir olması da başarılı sonuç için esastır. ${ }^{[12]}$

\section{ALT EKSTREMITE FONKSIYONLARINA YÖNELIK TEDAVILER}

Serebral palsili çocuklarda yürüme becerisi nörolojik defisitin tipi ve şiddeti ile ilişkilidir. Ancak eşlik eden diğer anomaliler, emosyonel, davranışsal ve motivasyonel faktörler de bu süreçte önemlidir. Kişinin fiziksel, sosyal ve kültürel çevresi ve alabildiği tıbbi bakım ve destekten de kuşkusuz etkilenmektedir. Kaba motor fonksiyon düzeyi I-III arasında olan hastalarda bağımsız ya da destekli hareketliliğin sağlanması rehabilitasyon yaklaşımlarının en önemli hedefidir. Bu amaçla kullanılan tedavi yaklaşımları ile tonusun azaltılması, eklem hareket açıklıklarının korunması, deformite oluşumunun önlenmesi, denge, koordinasyon ve kas gücünün artırılması hedeflenmektedir. Bunun sağlanmasında rehabilitasyon yaklaşımları, ortopedik ve nöroşirürjikal girişimler ile tonus anormalliklerine ve deformitelere müdahale edilmesi gerekmektedir. Erken çocukluk döneminde tedavide rehabilitasyon yaklaşımları öncelikli iken çocuğun büyümesi ile birlikte işlevsel düzelmelerin sağlanması ancak multidisipliner bakış ve tedavi ile mümkün olmaktadır. ${ }^{[13]}$

\section{GÜÇLENDIRME EGZERSiZLERi}

Serebral palsili çocuklarda güçsüzlüğe bağı kas lifi çapındaki azalma nedeni ile aponeuroz uzunluğunda kısalma olduğu gösterilmiştir. Bu nedenle kasın normal uzunluğunu koruyabilmesi için spastisitesi olan ve olmayan tüm serebral palsili çocuklarda güçlendirme egzersizleri önerilmelidir. Önceleri güçlendirme egzersizlerinin spastisiteyi artırdığı şeklinde bir bakış açısı ile bu tür egzersizlerden kaçınılırken artık güçlendirme programlarının spastisitede artış gibi bir olumsuz etkisinin de olmadığı gösterilmiştir. Güçlendirme egzersizlerinin kas gücünü artırıcı etkisi gösterilmiş, ancak motor fonksiyon, katılım ve yaşam kalitesi üzerindeki etkinliğini göstermek için yeterli çalışma olmadığı bildirilmiştir. Çoğu çalışmada süre, doz ve uygulama sıklığı yetersiz olarak bildirilmiştir. ${ }^{[14]}$

\section{TREADMILL ILE YÜRÜME EĞiTiMi}

Alt ekstremitede de göreve özgün olarak yapılan daha yoğun ve tekrarlayıcı lokomotor eğitim, treadmill ve kısmi vücut ağırlığı destekli treadmill uygulamaları şeklinde başlamıştır. 1980'li yıllarda spinal yaralanmalı kedilerde parsiyel vücut ağırlığı desteklenerek yapılan yürüme eğitimleri ${ }^{[15,16]}$ daha sonra insanlarda uygulanmaya başlamıştır. ${ }^{[17]}$ Hızın ayarlanabilmesi, yürüme sırasında verilen uyarılarla yürüme biçiminin düzeltilmesi avantajlarıdır. Özellikle diz ektansör ve fleksör kaslarının güçlenmesi ve dengenin iyileşmesi mümkün olmaktadır. Bunlar da çocuğun işlevsel kazanç elde etmesini sağlayan önemli faktörlerdir. Erişkin serebral palsili hastalarda yapılan bir çalışmada, yürüme bandı ile yapılan yürüme eğitiminin sonrasında hem yürüme bandında ve hem de yürüme bandı dışında yürüme etkinliğinin arttığı ve enerji harcanmasını azalttığı gösterilmiştir. ${ }^{[18]}$ Yürüme bandı ile yapılan geriye yürüme çalışmalarının kaba motor fonksiyon ölçütünde, ağırlık taşıma simetrisinde ve yürüme parametrelerinde düzelme sağladığı gösterilmiştir. Geriye doğru yapılan yürümede kaslar, öne yürümeye göre daha uzun süre aktif kalmakta ve kas gücü kazancı da daha çok olmaktadır. Ancak bu şekilde yürümeye adapte olabilmek yüksek düzeyde algılama ve fiziksel performans gerektirmektedir. ${ }^{[19]}$ Kalitatif ve kantitatif yürüme analizi ile değerlendirme yapılan 8 çalışmanın yer aldığı bir meta analizde treadmill ile yapılan yürüme eğitiminin yürüme endüransı, yürüme hızı ve destek zamanı üzerinde düzelme sağladığı kadans ve adım uzunluğu üzerinde ise etkili olmadığı bildirilmiştir. ${ }^{[20]}$

\section{ROBOT YARDIMLI TEDAVILER}

Teknolojinin kullanımı ile birlikte rehabilitasyon alanına giren pek çok uygulamadan birisi de robotik 
sistemlerin kullanılmaya başlanması olmuştur. Robot yardımlı tedaviler özgün eklem hareketlerinin robot yardımıyla yapıldığı, kısa sürede çok sayıda hareketin yapılmasına imkân sağlayan, kinematik ve kinetik ölçümlerin yapılabildiği sistemlerdir. Tedavi sırasında görsel, duysal ve işitsel geribildirim uygulanabilir. Kortikal reorganizasyonun sağlanması hareketin yoğunluğu ve sıklığı ile doğrudan ilişkilidir. Bu amaçla teknolojik cihazların rehabilitasyonda kullanımı da giderek yaygınlaşmaktadır. Robotik yardımlı yürüme sistemleri doğal fizyolojik yürüme biçimini bilgisayar kontrollü robotik bir ortez aracılığıyla sunan gelişmiş bir yürüyüş sistemidir. Geleneksel tedavilerin ya da vücut ağırlığı destekli sistemlerin kullanımı sırasında, iki ya da üç fizyoterapistin desteği ve yönlendirmesi gerekmekte iken robotik rehabilitasyon sistemleri tek bir kullanıcının uygulayabileceği etkin bir tedavi yöntemi haline gelmiştir. Maliyetin yüksek olması tedaviye ulaşılabilirliği sınırlayan önemli bir dezavantajlarıdır. [21] Robotik tedavilerin hem üst hem alt ekstremitelerde uygulanma şekli mevcuttur. Bu konuda yapılan ilk çalışmalar olgu sunumları ya da olgu serileri şeklinde başlamış ve sonrasında da birkaç randomize çalışma yayımlanmıştır. 2017 yılında yayımlanan bir sistematik derlemede 17 çalışma değerlendirilmiş ve bunlardan yalnızca iki randomize kontrollü çalışma kalitatif analize alınmıştır. Bu meta-analiz robotik yürüme sistemlerinin çocuklarda yürümenin üzerindeki etkinliği konusunda zayıf ve çelişkili kanıt olduğunu bildirmiştir. ${ }^{[22]}$ Çoğu olumlu sonuçların olgu bazlı olarak bildirildiğini vurgulamıştır. Bu nedenle hekim olarak robotik tedaviye yönlendirilen hastalardaki sonuçların yakından izlenmesi önerilmiştir. Randomize çapraz geçişli bir başka çalışmada, 6-18 yaş arası, bilateral spastik serebral palsili, kaba motor fonksiyon düzeyi II-IV arasında olan 16 hastanın sonuçları yayımlanmış ve robot yardımlı yürüme eğitiminin tek başına yürüme becerilerinin düzelmesi üzerine etkili olmadığı, bütüncül bir tedavi yaklaşımı içinde yer alması gerektiği vurgulanmıştır. ${ }^{[23]}$

\section{SANAL GERÇEKLIK TEDAVISi}

Sanal gerçeklik, içinde ses ve gerçek dünyaya benzeyen obje ve olaylar olan, bilgisayar ile tasarlanmış interaktif simülasyonların kullanımı olarak tanımlanmaktadır. Kullanıcı sanal objeleri hareketle (manipüle ederek) onlarla etkileşime girmektedir. Sanal gerçeklik sistemleri ve oyunları çocuklara daha uzun süreli, yoğunluk ve sıklığı daha fazla olan bir egzersiz ortamı oluşturmaktadır. Gerçek hayata benzer bir çevre ortamı yaratan bu sistemlerde görev özgün egzersizler yapılabilmektedir. Sanal ortamda egzersizin zorluğu ayarlanarak, çocuk oyun oynarken gereken zorlanma düzeyi sağlanabilmektedir. Vizüel ve işitsel geri bildirimler verilebilmekte ve problem çözme becerisi ile motor öğrenme kapasitesi artırılarak nöroplastisitede değişikliklere yol açmaktadır. Oyun ve animasyon özelliği çocuğun motivasyonunu ve katılımını artırmaktadır. ${ }^{[24]}$ Sanal gerçeklikle ilgili çalışmaların büyük çoğunluğu üst ekstremite fonksiyonu ve denge ile ilgilidir. Bu durumun mevcut ve geliştirilen sistemlerin üst ekstremite kullanımına uygun olması ile ilişkili olduğu düşünülmektedir. Sanal gerçeklik uygulamalarının küçük çocuklardaki sonuçları daha iyidir. Bu sonuç erken yapılan tedavilerin beyin plastisitesi ve adaptasyon yeteneği ile küçük çocuklarda daha başarılı olması ile açıklanabilir. Sanal gerçeklik tedavilerinde de uygulanan tedavi süresinin fazla olması sonuçların daha iyi olmasını sağlamıştır. ${ }^{[25]}$

\section{TRANSKRANIYAL DOĞRU AKIM TEDAVISi}

İnvaziv olmayan beyin simülasyonları tanısal ve tedavi amaçlı elektrik akımlarının beyine uygulandığı tedavi yöntemleridir. Bu amaçla transkranial manyetik simülasyon ve transkranial doğru akım tedavileri kullanılmaktadır. Çocuklarda daha çok kullanılan transkranial doğru akım tedavisidir ve nörolojik hastalıklarda kortikal plastisiteyi artırma ve motor fonksiyonu iyileştirme potansiyeli nedeni ile giderek daha fazla üzerinde durulan bir tedavi yöntemidir. Düşük yoğunluklu, sürekli, doğru akım primer motor kortekse kafatası üzerinden uygulanır. Kullanılan stimülasyon parametrelerine bağlı olarak kortikal eksitabilite ya da inhibisyon ortaya çıkarır. Transkranial doğru akım tedavisi kortikal uyarılabilirliği, intrakortikal inhibisyonu ve kortikal plastisiteyi değiştirerek nöromodülatuvar bir etki yapmaktadır.[26] Özellikle hemiplejik tip serebral palsili çocuklarda "interhemisferik imbalans" nedeni ile sağlam hemisferde ortaya çıkan aktivite artışının lezyonlu hemisferde aktivite azalmasına yol açtığı gösterilmiştir. Transkranial doğru akım uygulamaları ile lezyonlu hemisferin anodal uyarılması onun aktivitesini artırırken, sağlam hemisferde yapılan katodal uyarılar da sağlam hemisferde inhibisyon yaratıp interhemisferik inhibisyonu azaltmakta ve lezyonlu hemisferin upregülasyonuna neden olmaktadır. ${ }^{[27]}$

Bu konuda yapılmış çalışmaların meta-analizleri tedavinin pediatrik hastalıklarda kullanılabilecek güvenli bir yöntem olduğunu ve yürüme parametrelerinin bazılarında ve involenter hareketlerde iyileşme sağlayabileceğini bildirmektedir. Denge ve üst ekstremite fonksiyonları üzerine olan çalışmalarda sınırlı etkinlik bildirilmektedir. ${ }^{[27,28]}$

\section{KARDIYORESPIRATUVAR ENDÜRANS ÇALIŞMALARI}

Serebral palsili çoğu çocukta, adolesan ve erişkinde kardiyorespiratuvar dayanıklılık, kas gücü ve fiziksel 
aktivitelere katılma alışkanlığının daha az olduğu bilinmektedir. Bu da kardiyovasküler ya da tüm kronik hastalıklar nedeni ile ortaya çıkan mortalite ve morbidite oranının serebral palsili kişilerde çok daha fazla olduğu ve yaşlanmanın erken ortaya çıktığını göstermektedir. Uygun egzersiz programları ile serebral palsili çocuk ve erişkinlerde kardiyorespiratuvar fonksiyonun artırılabilmesi söz konusudur. Önerilen haftada 2-3 kez, en az 20 dakika, pik (en yüksek) kalp hızının \%60-95'inde, haftada iki seans çalışılıyorsa 16 hafta, haftada üç seans çalışılıyorsa sekiz hafta ardışık yapılan egzersiz programlarıdır. ${ }^{[29]}$ isşlevsel egzersiz programlarının (aerobik, anaerobik egzersizler ve güçlendirme egzersizleri) fiziksel uygunluğu, yaşam kalitesini artırdığı ve statik bisikletin veya yürüme bandında yapılan çalışmaların spastisite artışı ya da anormal hareket biçimlerinde artış gibi bir yan etkiye yol açmadan yürüme ve kaba motor işlevde düzelmeler sağladığı bildirilmiştir. ${ }^{[30]}$

Geçmişte serebral palsi konusundaki yayınlar erken çocukluk ve çocukluk dönemindeki bakım ve tedaviler konusunu ele alırken, günümüzde ergen ve erişkin dönemdeki serebral palsililerin sorunları ve gelecekte onları bekleyen olumsuzluklar ve bunları önleme yöntemleri üzerinde de çok daha fazla durulmaya başlanmıştır. 2019 yılında yayımlanan NICE (National Institute for Health and Care Excellence) kılavuzunda ${ }^{[31]}$ erişkin dönemde osteoporoz ve kırık riski artışı, kemik ve eklem sorunları (osteoartrit, servikal instabilite, spondiloz, spinal deformiteler, kalça, bilek ve omuz subluksasyonları, biyomekanik diz sorunları, ayak sorunları), mental sağlık sorunları, solunum problemleri ve ağrı, üzerinde durulan ve erişkin dönemde kişinin yaşam kalitesini kötüleştirerek katılımını azaltan sorunlar olarak vurgulanmaktadır.

Serebral palside kullanılan tüm rehabilitasyon yöntemlerinin, medikal tedavi ve cerrahi uygulamaların kanıtlar eşliğinde sunulduğu ve kanıt düzeyine göre sıralandığı bir derlemede öneriler şu şekildedir ${ }^{[32]}$ : Motor fonksiyonu tedavi etmeye yönelik yaklaşımlar olarak; bimanuel alıştırmalar, aktivite gözlem alıştırmaları, kısıtlamalı zorunlu kullanım tedavisi, işlevsel çiğneme eğitimi, hedefe yönelik alıştırmalar, hedefe yönelik planlanmış ev programları, hareketlilik alıştırmaları, yürüme bandı alıştırmaları, kısmi vücut ağırlığı destekli yürüme bandı eğitimi ve botulinum toksin enjeksiyonu sonrasında uygulanan iş-meşguliyet tedavileri şeklindeki alıştırma temelli yaklaşımların etkinliği belirgin olarak gösterilmiştir. Yapılan alıştırmanın performansını artırmak için çevresel düzenlemeler ve zenginleştirmeler yapılması, motivasyonu, dikkati ve tedavi uygulanabilirliğini artırmaktadır. Göreve özgün tedaviler sırasında kombinasyon olarak uygulanan elektrik simülasyonu, hidroterapi, bantlama, transkranial doğru akım tedavisi ve sanal gerçeklik ile oynanan oyunların da tedavi sonuçlarını pozitif etkilediği görülmektedir.

Tonus artışının tedavisinde önerilen tedavi yaklaşımları arasında; üst ve alt ekstremite spastisitesine yönelik botulinum toksin uygulamaları, selektif dorsal rizotomi, diazepam, intratekal baklofen etkinliği belirgin olarak gösterilen tedavi yaklaşımları sayılabilir. Baklofen, botulinum toksin ile birlikte fizyoterapi uygulamaları, transkranial doğru akım tedavisi, tüm vücut vibrasyon tedavisi, hipoterapi, tizanidin ve nörogelişimsel tedavi ve akupunktur spastisitenin azaltılmasında, derin beyin stimülayonu ve gabapentin distonide kanıtlarla önerilen tedavi yaklaşımlarıdır.

Sonuç olarak doksanlı yıllarda uygulanmaya başlanan botulinum toksin enjeksiyonları serebral palsi tedavisinde önemli bir yenilik olarak nitelenebilir. 2000'li yıllar da artık rehabilitasyonda tamamen bakış açısı ve yaklaşımın değişmesi ile aile ve çocuk odaklı ve aktivite temelli, beyin plastisitesinin gelişimini sağladığı kanıtlanmış tedavilerin gündeme geldiği bir dönem olmuştur.

\section{KAYNAKLAR}

1. Shepherd E, Salam AR, Middleton P, Han S, Makrides M, Mclntyre S, Badawi N, Crowther CA. Neonatal interventions for preventing cerebral palsy: an overview of Cochrane Systematic Reviews. Cochrane Database Syst Rev 2018;6:1176. Crossref

2. Bax $M$, Goldstein $M$, Rosenbaum $P$, Leviton $A$, Paneth $N$, Dan B, Jacobsson B, Damiano D. Proposed definition and classification of cerebral palsy, April 2005. Dev Med Child Neurol 2005;47(8):571-6. Crossref

3. Damiano DL. Activity, activity, activity: rethinking our physical therapy approach to cerebral palsy. Phys Ther 2006;86(11):1534-40. Crossref

4. Damiano DL. Rehabilitative therapies in cerebral palsy: the good, the not as good, and the possible. J Child Neurol 2009;24(9):1200-4. Crossref

5. Trabacca A, VespinoT, Liddo AD, Russo L. Multidisciplinary rehabilitation for patients with cerebral palsy: improving longterm care. J Multidiscip Healthc 2016;9:455-62. Crossref

6. Spittle A, Orton J, Anderson PJ, Boyd R, Doyle LW. Early developmental intervention programmes provided post hospital discharge to prevent motor and cognitive impairment in preterm infants. Cochrane Database Syst Rev 2015;(11):CD005495. Crossref

7. Ketelaar M, Vermeer A, Hart H, van Beek EP, Helders PJM. Effects of a functional therapy program on motor abilities of children with cerebral palsy. Phys Ther 2001;81(9):1534-45. Crossref

8. Arner M, Eliasson AC, Nicklasson S, Sommerstein K, Hägglund G. Hand function in cerebral palsy. Report of 367 children in a population-based longitudinal health care program.J Hand Surg Am 2008;33(8):1337-47. Crossref

9. Sakzewski L, Gordon A, Eliasson AC. The state of the evidence for intensive upper limb therapy approaches for children with unilateral cerebral palsy. J Child Neurol 2014;29(8):1077-90. Crossref 
10. Shierk A, Lake A, Haas T. Review of Therapeutic interventions for the upper limb classified by manual ability in children with cerebral palsy. Semin Plast Surg 2016;30(1):14-23. Crossref

11. Aarts PB, Jongerius PH, Geerdink YA, van Limbeek J, Geurts AC. Effectiveness of modified constraint-induced movement therapy in children with unilateral spastic cerebral palsy: a randomized controlled trial. Neurorehabil Neural Repair 2010;24(6):509-18. Crossref

12. Gordon AM. To constrain or not to constrain, and other stories of intensive upper extremity training for children with unilateral cerebral palsy. Dev Med Child Neurol 2011;53 Suppl 4:56-61. Crossref

13. Damiano DL, Alter KE, Chambers H. New clinical and research trends in lower extremity management for ambulatory children with cerebral palsy. Phys Med Rehabil Clin N Am 2009;20(3):469-91. Crossref

14. Ryan JM, Cassidy EE, Noorduyn SG, O'Connell NE. Exercise interventions for cerebral palsy. Cochrane Database Syst Rev 2017;6(6):CD011660. Crossref

15. Alaimo MA, Smith JL, Roy RR, Edgerton VR. EMG activity of slow and fast ankle extensors following spinal cord transection. J Appl Physiol 1984;56(6):1608-13. Crossref

16. Lovely RG, Gregor RJ, Roy RR, Edgerton VR. Effects of training on the recovery of full-weight-bearing stepping in the adult spinal cat. Exp Neurol 1986;92(2):421-35. Crossref

17. Werner C, Von Frankenberg S, Treig T, Konrad M, Hesse $S$. Treadmill training with partial body weight support and an electromechanical gait trainer for restoration of gait in subacute stroke patients: A randomized crossover study. Stroke 2002;33(12):2895-901. Crossref

18. Kim OY, Shin YK, Yoon YK, Ko EJ, Cho SR. The Effect of Treadmill Exercise on Gait Efficiency During Overground Walking in Adults With Cerebral Palsy. Ann Rehabil Med 2015;39(1):25-31. Crossref

19. Kim SG, Ryu YU, Je HD, Jeong JH, Kim HD. Backward walking treadmill therapy can improve walking ability in children with spastic cerebral palsy: a pilot study. Int J Rehabil Res 2013;36(3):246-52. Crossref

20. Han YG, Yun CK. Effectiveness of treadmill training on gait function in children with cerebral palsy: meta-analysis. J Exerc Rehabil 2020;16(1):10-9. Crossref

21. Tefertiller C, Pharo B, Evans N, Winchester P. Efficacy of rehabilitation robotics for walking training in neurological disorders: A review. J Rehabil Res Dev 2011;48(4):387-416. Crossref

22. Lefmann S, Russo R, Hillier S. The effectiveness of roboticassisted gait training for paediatric gait disorders: Systematic review. J Neuroeng Rehabil 2017;14:1. Crossref
23. Ammann-Reiffer $C$, Bastiaenen $\mathrm{CHG}$, Meyer-Heim AD, van Hedel HJA. Lessons learned from conducting a pragmatic, randomized, crossover trial on robot-assisted gait training in children with cerebral palsy (PeLoGAIT). J Pediatr Rehabil Med 2020;13(2):137-48. Crossref

24. Levac D, Rivard L, Missiuna C. Defining the active ingredients of interactive computer play interventions for children with neuromotor impairments: a scoping review. Res Dev Disabil 2012;33(1):214-23. Crossref

25. Chen Y, Fanchiang HCD, Howard A. Effectiveness of virtual reality in children with cerebral palsy: A systematic review and meta-analysis of randomized controlled trials. Phys Ther 2018;98(1):63-77. Crossref

26. Krishnan C, Santos L, Peterson MD, Ehinger M. Safety of noninvasive brain stimulation in children and adolescents. Brain Stimul 2015;8(1):76-87. Crossref

27. Fleming $M K$, Theologis $T$, Rachel $B$, Johansen-Berg $H$. Transcranial direct current stimulation for promoting motor function in cerebral palsy: a review. J Neuroeng Rehabil 2018;15(1):121. Crossref

28. Saleem T, Crasta JE, Slomine BS, Cantarero GL, Suskauer SJ. Transcranial direct current stimulation in pediatric motor disorders: A systematic review and meta-analysis. Arch Phys Med Rehabil 2019;100(4):724-38. Crossref

29. Verschuren O, Peterson MD, Balemans AC, Hurvitz EA. Exercise and physical activity recommendations for people with cerebral palsy. Dev Med Child Neurol 2016;58(8):798808. Crossref

30. National Institute for Health and Care Excellence. Cerebral palsy in adults. NICE guideline [NG119]. Published: 15 January 2019. https://www.nice.org.uk/guidance/ng119

31. Slaman J, Roebroeck M, van der Slot W, Twisk J, Wensink A, Stam H, van den Berg-Emons R. LEARN 2 MOVE Research Group. Can a lifestyle intervention improve physical fitness in adolescents and young adults with spastic cerebral palsy? A randomized controlled trial. Arch Phys Med Rehabil 2014;95(9):1646-55. Crossref

32. Novak I, Morgan C, Fahey M, Edmondson MF, Galea C, Hines A, Langdon K, Mc Namara M, Paton MCB, Popat H, Shore B, Khamis A, Stanton E, Finemore OP, Tricks A, te Velde A, Dark L, Morton N, Badawi N. State of the evidence traffic lights 2019: Systematic review of interventions for preventing and treating children with cerebral palsy. Curr Neurol Neurosci Rep 2020;20(2):3-21. Crossref 